\title{
Cross-Roll Flow Forming of ODS Alloy Heat Exchanger Tubes For Hoop Creep Enhancement
}

\section{Quarterly Technical Progress Report Jul $1^{\text {st }} 2004-S e p 30^{\text {th }} 2004$}

\author{
Principal Investigator:
}

Bimal K. Kad

Department of Structural Engineering

University of California-San Diego, La Jolla, CA 92093-0411

Tel: (858) 534 7059; Fax: (858) 534-6373; e-mail: bkad@ucsd.edu

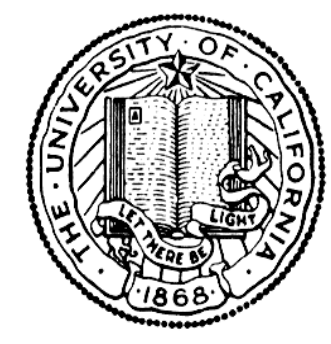

Issue Date November $30^{\text {th }} 2004$

National Energy Technology Laboratory Contract Award: DE-FC26-03NT41985

For

Development of Technologies and Capabilities for Developing Coal, Oil and Gas Energy Resources 
This report was prepared as an account of work sponsored by an agency of the United States Government. Neither the United States Government nor any agency thereof, nor any of their employees, makes any warranty, expressed or implied, or assumes any legal liability or responsibility for the accuracy, completeness, or usefulness of any information, apparatus, product, or process disclosed, or represents that its use would not infringe privately owned rights. Reference herein to any specific commercial product, process, or service by trade name, trademark, manufacturer, or otherwise, does not necessarily constitute or imply its endorsement, recommendation, or favoring by the United States Government or any agency thereof. The views and opinions of authors expressed herein do not necessarily state or reflect those of the United States Government or any agency thereof. 


\title{
Cross-Roll Flow Forming of ODS Alloy Heat Exchanger Tubes For Hoop Creep Enhancement
}

\begin{abstract}
Mechanically alloyed oxide dispersion strengthened (ODS) Fe-Cr-Al alloy thin walled tubes and sheets, produced via powder processing and consolidation methodologies, are promising materials for eventual use at temperatures up to $1200^{\circ} \mathrm{C}$ in the power generation industry, far above the temperature capabilities of conventional alloys. Target end-uses range from gas turbine combustor liners to high aspect ratio (L/D) heat exchanger tubes. Grain boundary creep processes at service temperatures, particularly those acting in the hoop direction, are the dominant failure mechanisms for such components. The processed microstructure of ODS alloys consists of high aspect ratio grains aligned parallel to the tube axis, a result of dominant axial metal flow which aligns the dispersoid particles and other impurities in the longitudinal direction. The dispersion distribution is unaltered on a micro scale by recrystallization thermal treatments, but the high aspect ratio grain shape typically obtained limits transverse grain spacing and consequently the hoop creep response. Improving hoop creep in ODS-alloy components will require understanding and manipulating the factors that control the recrystallization behavior, and represents a critical materials design and development challenge that must be overcome in order to fully exploit the potential of ODS alloys.

The objectives of this program are to 1) increase creep-strength at temperature in ODS-alloy tube and liner components by $100 \%$ via, 2) preferential cross-roll flow forming and grain/particle fibering in the critical hoop direction. Recent studies in crossrolled ODS-alloy sheets (produced from flattened tubes) indicate that transverse creep is significantly enhanced via controlled transverse grain fibering, and similar improvements are expected for cross-rolled tubes. The research program outlined here is iterative in nature and is intended to systematically i) prescribe extrusion consolidation methodologies via detailed test matrices, ii) examine and identify post-extrusion forming methodologies to create hoop strengthened tubes, which will be iii) evaluated at 'inservice' loads at service temperatures and environments. This research program is being conducted in collaboration with the DOE's Oak Ridge National Laboratory and the vested industrial partner Special Metals Corporation. In this fourth quarter of performance, program activities are continued for Tasks 2, 3 and 4 and are reported herein. The completion of Task 1 ensures sufficient materials are now available for the remainder of this program.
\end{abstract}




\section{Cross-Roll Flow Forming of ODS Alloy Heat Exchanger Tubes For Hoop Creep Enhancement}

Table of Contents

1. Executive Summary 1

2. Experimental Task Structure 3

3. Experimental Program Activity 3

4. Results and Discussion 5

5. Conclusions 6

$\begin{array}{ll}\text { 6. References } & 6\end{array}$ 


\section{$\S 1$. Executive Summary}

Oxide dispersion strengthened (ODS) ferritic alloys based on FeCrAl and intermetallic $\mathrm{Fe} 3 \mathrm{Al}$ alloys are promising materials for high-temperature, high-pressure tubing, liner and shell applications on account of their creep strength at very high temperatures and excellent corrosion resistance in oxidizing, oxidizing/sulphidizing and oxidizing/chlorinating environments compared to available high-temperature alloys. Requirements for such a combination of properties are found in advanced systems being developed for utilization of fossil fuels, such as the DOE's Vision 21 and FutureGen programs and in improved gas turbines being developed for power generation.

The creep strength of conventional high-temperature alloys decreases rapidly with increasing temperature, as shown in Fig. 1, since the thermodynamic stability of the various available strengthening phases also decreases with increasing temperature ${ }^{1}$. Also shown in Fig. 1 is the significant increase in temperature capability afforded when a dispersion of inert oxide particles is used as the strengthening phase. A major feature of oxide dispersion-strengthened alloys is that the most successful route for their preparation appears to involve powder metallurgical processing ${ }^{2-6}$. Further, the critical need to maintain the fine size, volume fraction, and uniform distribution of the oxide particles in the alloy matrix, as well as the need to develop specific grain shapes, results in some significant differences in alloy fabricability and in the application of joining procedures, compared to conventional cast and wrought alloys. Hence, while ODS alloys offer a significant increase in temperature capability, they have a limited formability envelope, their mechanical properties are very anisotropic, and they cannot be joined by conventional fusion welding processes. Thus, the exploitation of the full capabilities of ODS alloys is limited until these critical hurdles are addressed and overcome.

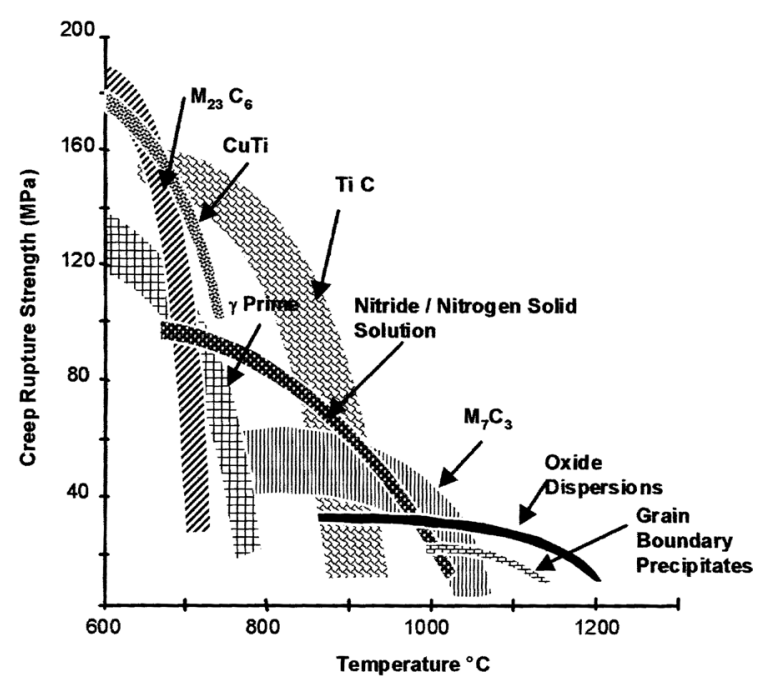

Figure 1. The creep performance envelope as a function of strengthening phase [1].

Our current program target is envisaged as a demonstration of the applicability of ferritic and $\mathrm{Fe}_{3} \mathrm{Al}$-based ODS alloys in the high temperature heat-exchanger tubing as proposed under the proposed DOE and NETL Vision-21 program metrics, intended to sustain internal pressures (P) of up to $1000 \mathrm{psi}$ at service temperatures of $1000-1200^{\circ} \mathrm{C}$. Within the framework of this target application, the development of suitable mechanically alloyed ferritic $\mathrm{FeCrAl}$ and intermetallic $\mathrm{Fe}_{3} \mathrm{Al}$ alloy materials and processes must strive to deliver a combination of high mechanical strength at temperature and prolonged creep-life in service. Such design requirements are often at odds with each other as strengthening measures severely limit the as-processed grain size detrimental to creep life. The extrusion consolidation processes currently employed cause material flow in the longitudinal direction, resulting in extreme dispersoid and powder surface impurity fibering in the axial direction in ODS materials. Thus, elongated grains are produced aligned parallel to the longitudinal direction, with a fine grain spacing in the hoop direction. The basic problem of limited hoop creep is illustrated in Figure 2a,b within the context of the existing 
underlying grain structure. Fortunately ODS-alloys do exhibit intrinsic creep strength sufficient to meet design requirements albeit that this performance is only exhibited in the longitudinal direction. Ultimate failure in transverse (hoop) creep involves creep cavity concentration, Figure $2 \mathrm{~b}$, which strongly depends on the dominant grain boundary orientation with respect to the loading axis, Figure 47 . Such fibering, unless altered by post-flow forming, is expected to thwart attempts to arrive at the large transverse grain $\operatorname{size}^{3,8}$ considered essential for improved creep performance in the hoop direction. Clearly what is required is to devise a means of effecting material flow in directions other than longitudinal that would reorient the primary fibering axis of dispersoids and impurities in the hoop direction.

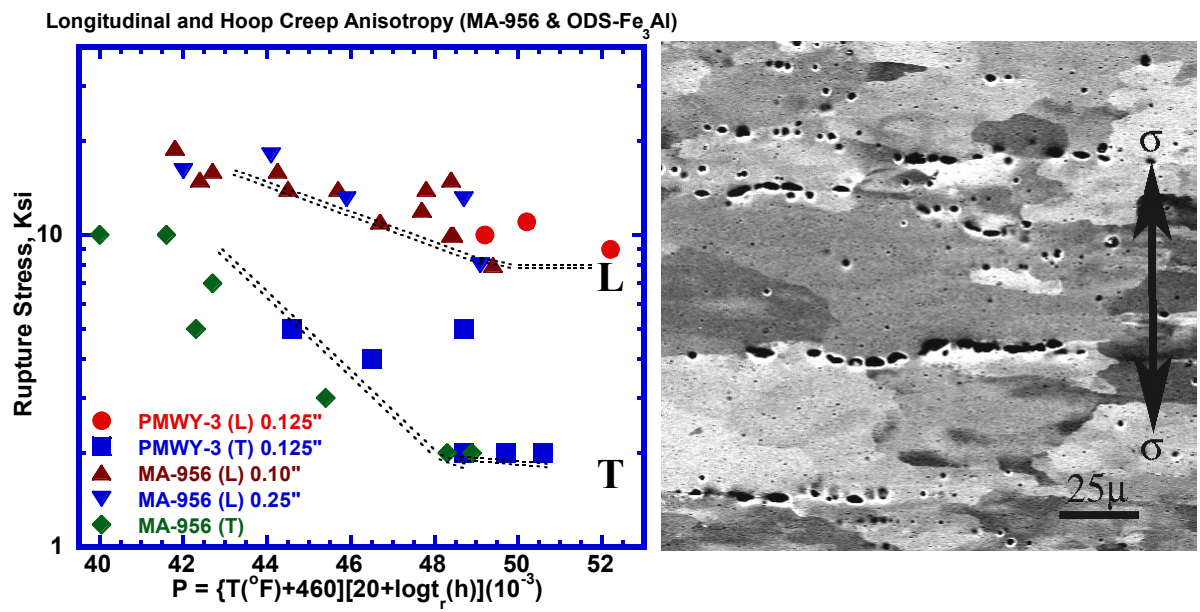

Figure 2. Longitudinal (L) vs. transverse (T) creep anisotropy in $\mathrm{Fe}_{3} \mathrm{Al}$ (PMWY3) and MA-956 tubes._b) Creep cavitation observations in hoop creep loading tests.

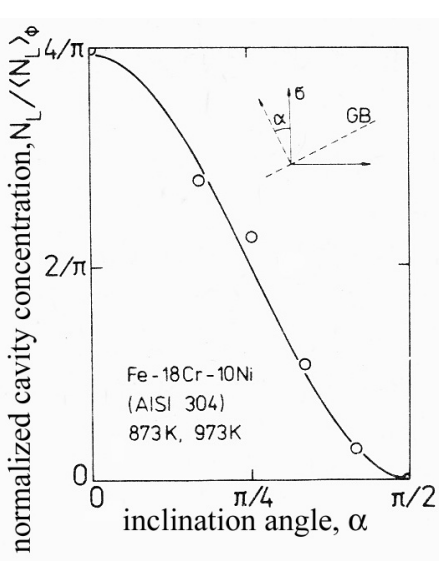

Figure 3. Creep cavity density as $f_{n}(\mathrm{~GB}$ orientation $)$ with respect to the loading axis [7].

Thus, our research objective is to modify tube-processing methodologies by incorporating cross-roll forming to create the underlying microstructure that will meet or exceed the design 'inservice' creep-life requirements of such ODS-alloy heat exchanger tubes. We are examining microscopic, microstructural and morphological issues with a view to addressing optimum material design for macroscopic components for a well prescribed 'in-service' loading criteria. A set of program tasks were outlined in the initial submission and a list of anticipated milestones were submitted to NETL in Fall 2003. This quarterly report summarizes our research activity in the fourth quarter of performance period of July $1^{\text {st }} 2004$ - September $30^{\text {th }} 2004$.

In this quarterly performance period program work is continuing in Tasks 2, 3 and 4. Task 1 was completed earlier and will provide all program materials for the remaining tasks. Task 2 consisting of cross-rolling flat segments of tubes is continuing and will be engaged in iteratively. Samples of both the ODS-Fe 3 Al and FeCrAl (MA956) materials have been flattened at crossrolled. The ODS-Fe $3 \mathrm{Al}$ tubes are initially $1 \frac{11 / 4}{4} \mathrm{OD}, 1 / 8$ " wall thickness and the ODS-FeCrAl tubes are $2 \frac{1}{2}$ " OD, $1 / 4$ " wall thickness. Three different roll flattening processes are employed as 1) roll-longitudinally, 2) roll transverse to flatten and 3) roll flatten to $20-25 \%$ reduction in thickness. In Task 3, the capital equipment has been successfully identified and procured. This equipment is currently being relocated to UCSD and will be retrofitted to our task requirements. In Task 4, samples obtained from Task 2.1 are being examined for microstructure and mechanical performance in transverse (hoop) creep conditions. Initial creep tests of MA956 materials are reported here with more to be appended I later performance periods. 


\section{§ 2. Experimental Task Structure}

The experimental work reported here is described in the context of the task structure outlined below. For the duration of this program activity through September $30^{\text {th }} 2005$ and required reporting (monthly or quarterly) we will refer to this task structure for clarity and precise reference.

Task 1: Extrusion Consolidations, Tube and Sheet Forms: Completed

1.1 ODS-Powder materials - milling studies, impurity evaluation

1.2 Annular ODS-Alloy tube and sheet extrusions

Task 2: Rolling Studies for Optimum Fibering: Initiated \& Continuing

2.1 Single vs. cross-rolling evaluation, Parametric studies

2.2 Correlate cross-rolling strains and overall grain re-orientation

Task 3: Post-Extrusion Cross-Roll Rolling of ODS-tubes \& shells: Initiated \& Continuing

3.1 Helical/cross rolling for grain fibering

3.2 Computer model verification for torsional flow predictions

Task 4: Microstructure and Creep Performance Evaluation: Initiated \& Continuing

4.1 Recrystallization annealing: static and gradient

4.2 Microstructure characterization \& evaluation

4.3 Transverse creep and stress-rupture response

\section{§3. Experimental Program Activity}

Task 2.1: Single vs. cross-rolling evaluation, parametric studies: Flat sections of initial uniaxially rolled/extruded coupons to be cross-rolled via parametric evaluations of cross-grain fibering of the underlying grain structure.

Materials produced in Task 1.1 and 1.2 were sectioned and examined for microstructural details. No recrystallization was observed in either alloy materials as a result of this $900^{\circ} \mathrm{C}$ thermal-mechanical treatment. This flattened strip is the required material for the initial matrix of parametric cross-rolling studies of Task 2.1. Based on the post-forging microstructural evaluation, and in the interest of narrowing experimental windows, all further cross-rolling studies are to be conducted at $900^{\circ} \mathrm{C}$. Residual curvature in the forge-flattened specimens was eliminated via subsequent rolling as described here. Three separate rolling schemes were employed: 1) Rolling longitudinally in 0.01 " steps till the sample was measurably flat, 2) Rolling transversely to the tube axis in 0.01 " steps till the sample was measurably flat, and 3) Rolling transversely to effect a net $20-25 \%$ thickness reduction in the starting wall thickness. In the rolling schedule 3 , this large deformation was accomplished in steps of $4-5 \%$ reduction per pass with the sample reheated to $900^{\circ} \mathrm{C}$ for 15 minutes in the air furnace. The rolled flat samples were removed from their stainless steel wraps and prepared for the recrystallization treatments. Additional levels of (cross-rolling) strains will be evaluated in the next quarter. The cross-rolled 
specimens are recrystallized to create abnormal grain growth in such ODS-alloy coupons. The heat treatments are 1 -hour at $1200^{\circ} \mathrm{C}$ in air for $\mathrm{ODS}-\mathrm{Fe}_{3} \mathrm{Al}$ and a 1 -hour at $1375^{\circ} \mathrm{C}$ in air for $\mathrm{FeCrAl}$ (MA956). Microstructures reveal elongated grain shapes in the transverse orientation only for the sample cross-rolled $20-25 \%$ in the transverse orientation. It is likely that surface layers are affected in rolling schedule 1 and 2 but no changes are perceptible at the level of optical resolution.

Task 3: Cross-Roll Rolling: As part of this task UCSD has proposed to purchase and install a used rotary cross-rolling set up for all future cross-rolling operations of MA956 and ODSFe3Al tubes under this program and any future needs. Such equipment when acquired would require significant retrofit and redesign of the rolls to accomplish the tasks at hand.

Two Medart straighteners size ' 0 ' were identified for purchase in the previous performance period. Based on our discussions with vendors, an acquisition for a Two Roll Medart straightener from Bar Processing Corp in Warren, MI was initiated by UCSD. The machine has been successfully decommissioned from its existing installation and in the process of being relocated at UCSD. Once on site the retrofit and upgrade process will be implemented. The size ' 0 ' machine is capable of processing rod and bar in the size range of $1 / 4$ " $-1 \frac{1}{2}$ " and tubes in the size range $1 / 4 "$ " 2 ". The machine powered by a 30 HP machine is suitable to perform cross-rolling operations at near ambient temperatures in MA956 alloys. Note ODS-Fe3Al alloys on account of their low temperature brittleness can only be worked at temperatures sufficiently above $600^{\circ} \mathrm{C}$.

While the capital equipment acquisition is in progress, arrangements were made to perform sample trials of rotary cross rolling with a vendor. This effort has just gotten under way and full details and results will be reported in the next performance period.

Task 4.1: Recrystallization Annealing: Recrystallization strategies for creating abnormal grain growth in ODS alloy materials cross-rolled in Task 2.1 (and from Task 3 in later periods) suitable for transverse creep enhancements are listed in Table 1.

Table 1: Recrystallization matrix for cross rolled ODS-Fe3AI and MA956 materials

\begin{tabular}{|c|c|c|c|c|}
\hline HT Test\# & Material & HT: Temperature, ${ }^{\circ} \mathrm{C}$ & HT: Time, Hrs & Environment \\
\hline 1 & ODS-Fe 3 Al & $1200^{\circ} \mathrm{C}$ & $1 \mathrm{hr}$ & Air \\
\hline 2 & ODS-Fe 3 Al & $1200^{\circ} \mathrm{C}$ & $1 \mathrm{hr}$ & Argon \\
\hline 3 & ODS-MA956 & $1375^{\circ} \mathrm{C}$ & $1 \mathrm{hr}$ & Air \\
\hline 4 & ODS-MA956 & $1375^{\circ} \mathrm{C}$ & $1 \mathrm{hr}$ & Argon \\
\hline 5 & ODS-MA956 & $1400^{\circ} \mathrm{C}$ & $1 \mathrm{hr}$ & Air \\
\hline 6 & ODS-MA956 & $1400^{\circ} \mathrm{C}$ & $1 \mathrm{hr}$ & Argon \\
\hline
\end{tabular}

The heat-treatment temperatures are based on prior DOE funded work ${ }^{2-5}$ performed by the PI. The introduction of inert environment HT was initially applied to ODS-Fe 3 Al alloys ${ }^{3,8}$, which produced significant improvements in transverse creep. This inert treatment will be applied to ODS-MA956 alloys in the present study. In the current performance period HT tests 1, 2 and 3 have been complete for all cross-rolled materials from Task 2.1. Additional tests 4, 5 and 6 will be conducted later in the program.

Microstructures reveal elongated grain shapes in the transverse orientation for the samples cross-rolled $20-25 \%$ in the transverse orientation. It is likely that surface layers are affected in rolling schedule 1 and 2 but no changes were perceptible at the level of optical resolution. 
Task 4.3: Transverse Creep and Stress Rupture Response: The initial cross-rolled samples from Task 2, heat treated in Task 4.1 are spark machined to extract ASTM E-8 standard specimens from the transverse orientation. These are being evaluated in transverse creep tests initially being performed at a dead load $2 \mathrm{Ksi}$ stress at $900^{\circ} \mathrm{C}$ in air.

Figure 4 shows a typical response pattern of a MA956 cross-rolled sample (cross rolled 20\%) in creep tests. The sample exhibited a brief primary regime, an extended steady state regime followed by a tertiary (failure) regime. The y-axis gridline spacing denotes a creep strain of $2 \%$. Note that the sample fails at an overall strain of about $3 \%$ with the largest component of strain (about $2 \%$ ) occurring in the tertiary (failure) regime. The steady state creep rate is extracted as $9 \mathrm{e}^{-5} /$ day (note dashed red line on the linear portion of the curve) and based on a lifetime exposure of 1381 hours the Larsen Miller parameter is computed as 48.87 . This data is to be compared with the baseline data to be acquired from Oak Ridge National Laboratory.

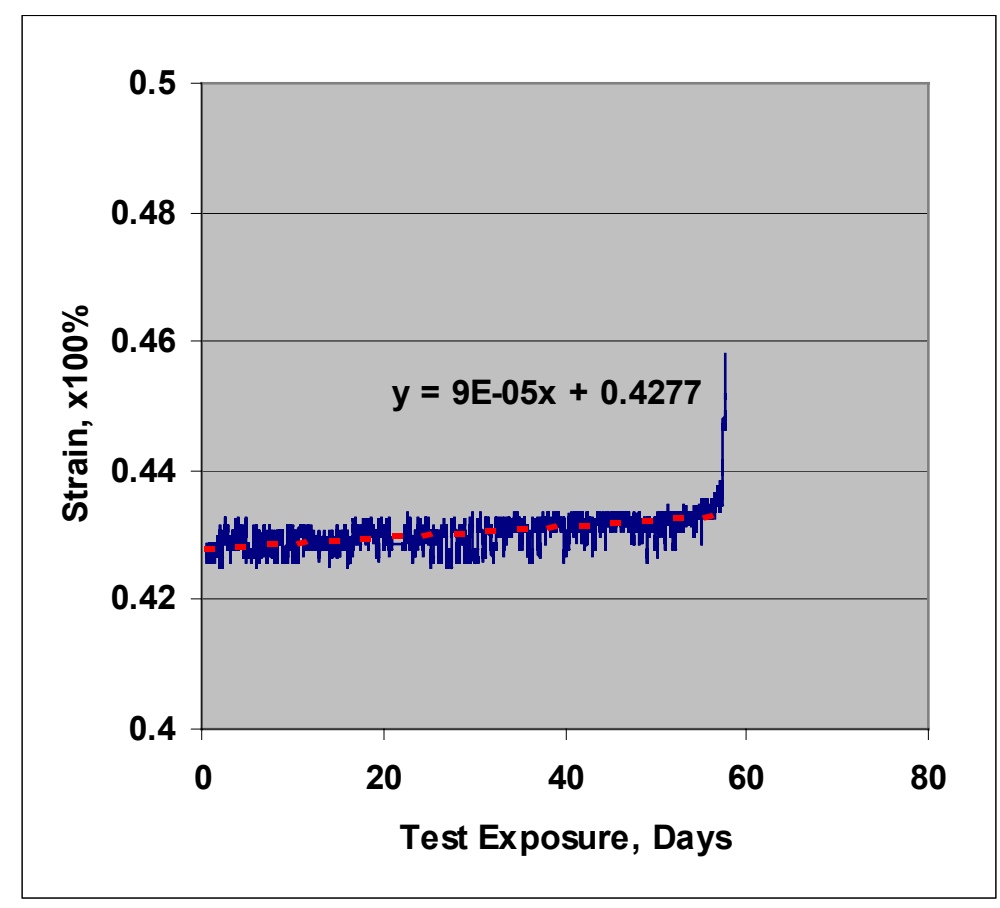

Figure 4. Creep test of a MA956 sample extracted from a $2 \frac{1}{2}$ " OD, $1 / 4$ " wall thickness tube and cross-rolled at $900^{\circ} \mathrm{C}$ to $20 \%$ reduction. Creep test conducted at $900^{\circ} \mathrm{C}$ at $2 \mathrm{Ksi}$ stress in air.

\section{§ 4. Results and Discussion}

The experimental program is proceeding at the originally prescribed timetable. The initial material preparation steps are well characterized and known from prior experience. Additional tasks 2 and 4 will yield much of the preliminary test data for quantifying the level of crossrolling strains necessary for the success of this program.

In the cross-rolling trials we note that significant grain alignment was recorded in the transverse direction, whereas none was observed in rolling schedule \#2 (see section on Task 2.1). It is unknown if lower levels of strain (say for example 5-10\%) will be sufficient to effect some grain organization. At the present time, samples cross-rolled $20 \%$ indicate a definite realignment of grains and further experiments are continuing with this level of deformation strain. Initial creep data on cross-rolled samples are now available with minimum creep rate/day in the high 10-5 range. We note that the samples fail with a large component of tertiary strain (see Figure 4) - with creep rates several magnitudes higher than in steady state. This change in strain rate can be deployed as a marker of the onset of failure both in laboratory tests and in industrial applications and practice. 


\section{§ 4. Conclusions}

The current research program was initiated on October $1^{\text {st }} 2003$ and is concluding its fourth quarter of performance. The project progress is on schedule with work initiated and continuing in Tasks 2, 3 and 4. Task 1 was completed earlier. MA956 materials have been successfully crossrolled and a minimum level of $20 \%$ deformation strain has been identified as necessary for grain realignment. These materials are now being tested in creep and will evaluated with reference to base creep data.

\section{References:}

1. F. Starr, in Materials for High-Temperature Power Generation and Process Plant Applications, A. Strang, Ed., IOM Communications Ltd., Book No. 728, pp. 79-152 (2000).

2. V.K. Sikka, I.G. Wright, and B.K. Kad, " Processing of Oxide-Dispersion-Strengthened $\mathrm{Fe}_{3}$ Al-Based Alloy Tube" (1998) $12^{\text {th }}$ Annual Fossil Energy Materials Conf., Knoxville, TN, May 12-14, 1998, p.11-19

3. B.K. Kad, C.G. McKamey, I.G. Wright and V.K. Sikka, "Optimization of ODS-Alloy Properties" (2002) $16^{\text {th }}$ Annual Fossil Energy Materials Conf., Baltimore, MD, April $22^{\text {nd }}-24^{\text {th }}$, 2002.

4. B.K. Kad, C.G. McKamey, I.G. Wright and V.K. Sikka, "High Temperature Mechanical Properties of ODS-Fe ${ }_{3} \mathrm{Al}$ Tubes" (2001) $15^{\text {th }}$ Annual Fossil Energy Materials Conf., Knoxville, TN, April $30^{\text {th }}$-May $2^{\text {nd }}, 2001$

5. B.K. Kad, V.K. Sikka, R.N. Wright and I.G. Wright, "Oxide Dispersion Strengthened $\mathrm{Fe}_{3}$ Al-Based Alloy Tubes" (2000) $14^{\text {th }}$ Annual Fossil Energy Materials Conf., Knoxville, TN, April 24-26, 2000; ibid (1999) $13^{\text {th }}$ Annual Fossil Energy Materials Conf., Knoxville, TN, May $11^{\text {th }}-14^{\text {t }}, 1999$.

6. J. Ritherdon, A.R. Jones and I.G. Wright, "The Recovery and Recrystallization of a Mechanically Alloyed ODS-Fe 3 Al Alloy" (2001) Materials Science Forum, 360-362, pp.217222, 2001

7. I.W. Chen and A.S. Argon, "Creep Cavitation in 304 Stainless Steel" (1981) Acta Metallurgica, 29, p.1321, 1981; ibid. "Diffusive Growth of Grain-Boundary Cavities" Acta Metallurgica, 29, p1759, 1981

8. B.K. Kad, I.G. Wright, V.K. Sikka and R.R. Judkins, (2004) "Optimization of Hoop Creep Response in ODS-Fe ${ }_{3} \mathrm{Al}$ Tubes" $18^{\text {th }}$ Annual Fossil Energy Materials Conf., Knoxville, TN, June $2^{\text {nd }}-4^{\text {th }}, 2004$ 